\title{
A water level relationship between consecutive gauge stations along Solimões/Amazonas main channel: a wavelet approach
}

\author{
R. D. Somoza, E. S. Pereira, E. M. L. Novo \& C. D. Rennó \\ Department of Remote Sensing, National Institute of Space Research, \\ Brazil
}

\begin{abstract}
Gauge stations are distributed along the Solimões/Amazonas main channel to monitor water level changes over time. Those measurements help quantify both the water movement and its variability from one gauge station to the next downstream. The objective of this study is to detect changes in the water level relationship between consecutive gauge stations along the Solimões/Amazonas main channel, since 1980. To carry out the analyses, data spanning from 1980 to 2010 from three consecutive gauges (Tefe, Manaus and Óbidos) were used to compute standardized daily anomalies. In particular for infra-annual periods it was possible to detect changes for the water level variability along the Solimões/Amazonas main channel, by applying the Morlet Wavelet Transformation (WT) and Wavelet Cross Coherence (WCC) methods. It was possible to quantify the waves amplitude for the WT infra-annual scaled-period and were quite similar to the three gauge stations denoting that the water level variability are related to the same hydrological forcing functions. Changes in the WCC was detected for the ManausÓbidos river stretch and this characteristic might be associated with land cover changes in the floodplains. The next steps of this research, will be to test this hypotheses by integrating land cover changes into the floodplain with hydrological modelling simulations throughout the time-series.

Keywords: fluviometric variabilities, wavelet cross coherence, Amazon floodplain.
\end{abstract}




\section{Introduction}

For any large river basin, the annual hydrological process are very important in terms of geomorphology, biochemistry and sediment transport, as well as the biota and biodiversity maintenance into the floodplain [1,2]. Surface fresh waters are also important for the management of water resources use by people. One of the biggest challenges in the 21 st century will be managing water availability and related global health and hazard prevention aspects [3].

Nowadays, the knowledge of space and time variations of continental waters relies on in situ gauge measurements and hydrological modelling. In situ gauge stations measurements help quantifying both the water movement and its variability from one gauge station to the next downstream. Changes in both, water movement and its variability along the time may be related to environmental changes in the river floodplain.

Remote sensing surveys along the Solimões/Amazonas main channel have shown large differences in floodplain land cover upstream and downstream Manaus [4]. In the last 30 years, almost half of the flood forest have been removed between Parintins and Almeirim [5]. From the hydrodynamic point of view, the roughness on this deforested areas move from a soft to a stiff blade, increasing both the friction coefficient and the superficial water velocity.

On this context, were selected the Manaus gauge station and two others representing upstream and downstream Manaus to explore the fluviometric measure data throughout the time series. The main objective of this study is to detect changes in the water level relationship between consecutive gauge stations along the Solimões/Amazonas main channel, since 1980, by applying a wavelet approach.

\section{Data and methodology}

\subsection{Study area}

The Amazon Basin is considered the largest hydrographic river basin in the world with 6.1 million $\mathrm{km}^{2}$, extending from the Andes to the Atlantic Ocean (Figure 1). In tropical areas, hydrographs of large river systems such as the Amazon River often have a peak annual flood, resulting from seasonal changes in precipitation [6].

The large range of annual variation in water level and inundated area (rivers and floodplains) in the Amazon basin is responsible for large seasonal changes in water mass [7]. The distribution of floodplain environments along the Solimões/Amazon River is strongly influenced by the rise and fall of its water level. In rivers with low slope gradients such as the Amazon, the input peak is usually higher than the output peak, resulting in a time lag in the hydrographs [8]. Due to the Amazon basin size, this time lag, can be larger than on month after the rainy season, in the Central Amazon near Manaus [1]. 


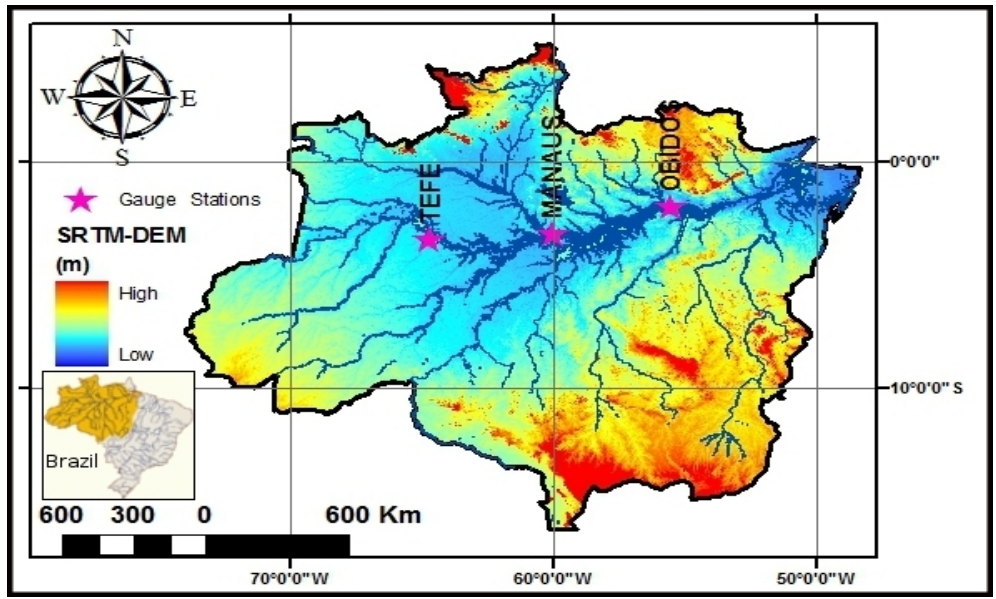

Figure 1: Study Area: Amazon River Basin.

\subsection{Gauge stations}

Three gauge station distributed form upstream to downstream were selected for this study: Tefe, Manaus and Óbidos (Figure 1). These stations are assumed to represent water level variation in the Amazon/Solimões main channel even when they are not exactly located in the main stem such as the case of Manaus gauge station. Those stations have an historical series of fluviometric records larger than 30 years (Table 1). All data was obtained freely from the Brazilian Hydrological Information System website (HIDROWEB, http: //hidroweb.ana.gov.br/)

Table 1: Fluviometric gauge station description. Water level-period is referring to the $1^{\text {st }}$ measurement when the time series begin.

\begin{tabular}{|c|c|c|c|}
\hline Gauge Station & Latitude & Longitude & Water level-period \\
\hline TEFÉ & $\mathrm{S} 3^{\circ} 22^{\prime} 33.6^{\prime \prime}$ & $\mathrm{W} 64^{\circ} 39^{\prime} 18.0^{\prime \prime}$ & Aug/1982 \\
\hline MANAUS & $\mathrm{S} 3^{\circ} 8^{\prime} 13.20^{\prime \prime}$ & $\mathrm{W} 60^{\circ} 1^{\prime} 37.20^{\prime \prime}$ & Sep/1902 \\
\hline ÓBIDOS & $\mathrm{S} 1^{\circ} 55^{\prime} 8.40^{\prime \prime}$ & $\mathrm{W} 55^{\circ} 30^{\prime} 46.80^{\prime \prime}$ & Dec/1927 \\
\hline
\end{tabular}

Since 1980, all available data of water level daily records from Manaus and Óbidos were used to carry out the analysis, while from Tefe the data was available since late 1982. Each data series was preprocessed in order to remove the outliers values and complete the series by using linear interpolation for gaps smaller than three days. Gaps larger than three days remain in the series and were not considered in the analyses. The Tefe data series had gaps from 1 week to 6 months on the 
following years: 1983, 1987, 1988, 1990, 1991, 1994 and 1995. There were no gaps in the Manaus and Óbidos data series.

\subsection{Computing method}

To carry out the analyses, data spanning from 1980 to 2010, described in Table 1, were used to compute the water level standardized anomalies [9]. First, the Morlet wavelet transformation (WT) was applied to each series and being computed 5\% of significance against the red noise model and the influence cone [10]. It was computed the Wavelet Cross Coherence (WCC) power spectrum of the water level standardized daily anomalies relations between consecutive Gauge stations: TefeManaus, Manaus-Óbidos [10, 11]. In order to validate the Wavelet Coherence, a Monte Carlo simulation was applied to obtain a 95\% confidence level for the WC against the red noise model as described in [11].

To carry out this study, a program written in python language was developed to help integrate all data and results into a relational data base (Sqlite). The connection with the data base and the program was made using the Database Abstract Layer (DAL) from the framework web2py [12]. This DAL organization provides advantages for consulting, manipulation and interoperability by date.

For the wavelet analysis a Python programming interface among routines originally written in Matlab by [11] was developed. These routines was accessed in python, by octave(http://www.gnu.org/software/octave/) language, using oct2py package (More details in: https://pypi.python.org/pypi/oct2py). However, some functionality of Matlab were not available in octave, in this case, a minor modification of the routines from [11] was done. The plot functions was reimplemented in pure python using matplotlib package (More details in: https://pypi.python.org/pypi/matplotlib/1.2.0). The final version of this Python programming interface package, that it was called as Piwavelet, was released under general GNU license version 3, and, it was located for free access in the web site http://duducosmos.github.com/PIWavelet/.

\section{Wavelet transform}

The Wavelet Transform (WT) has emerged in recent years as a powerful timefrequency analysis and signal coding tool favoured for complex non-stationary signals. It is a tool for characterizing the frequency, the intensity, the time position, and the duration of variations in hydro-meteorological series [13]. Using WT, time series can be decomposed into time-frequency space, determining both the dominant modes of variability and how these modes vary in time [10].

Figure 2 depicts the standardized daily water level and the global wavelet spectrum (WT integration throughout the time-series) for the tree gauge stations, over the 1980-2010 period. The water level, for all gauges, in consequence of their locations in the tropics, is characterised by a strong annual cycle and superimposed with a visible inter-annual variability [14] (Figure 2 on top). Considering annual and infra annual scales, the Global power spectra shows an 
strong annual components (Power $\approx 10^{7} \mathrm{~cm}^{2}$ ) for all wavelet signals. This characteristic is masking the other signals energy that might come from higher or lower frequencies.

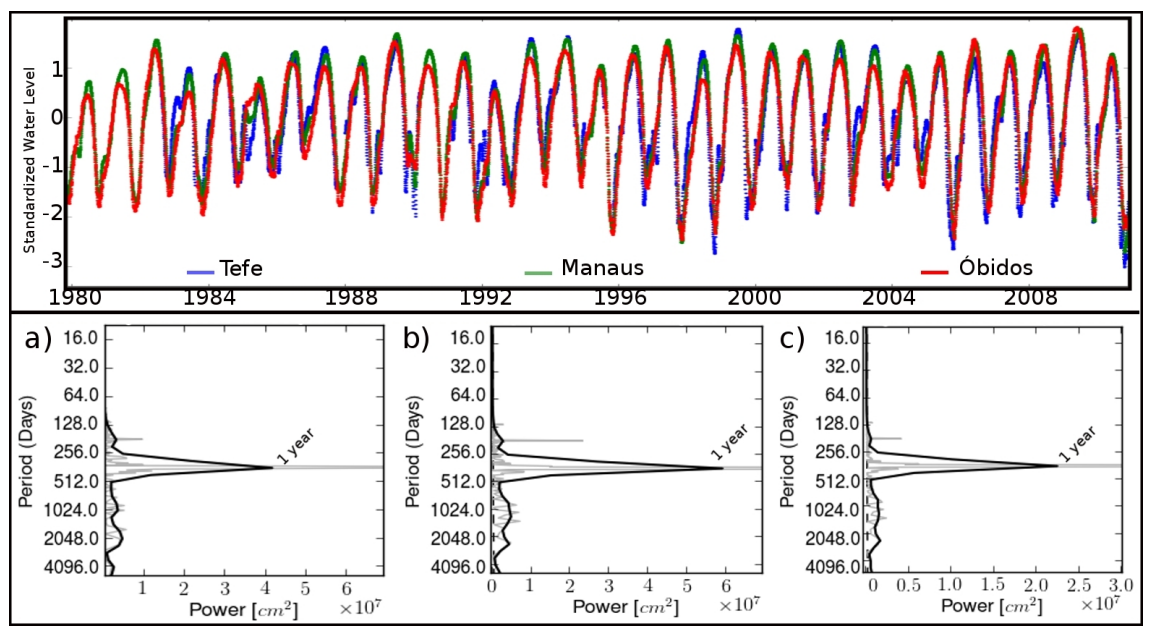

Figure 2: Standardized daily water level on the top, Y-axis are the anomalies values $(\mathrm{cm} / \mathrm{cm})$ and the $\mathrm{X}$-axis are time (years). Global wavelet spectrum $\left(\mathrm{cm}^{2}\right)$, for the Gauge stations: (a) Tefe, (b) Manaus, and (c) Óbidos.

Due the annual climatological cycle were very strong, this feature was removed from the historical series by using the daily climatological mean into the standardized anomalies calculi (Figure 3(b)). This way, the global wavelet spectrum (GWPS) was zoomed to make it possible to observe multi-annual scales, which have already been described in literature. For example, Óbidos gauge station has been described by the wavelet of watershed monthly mean variability and characterizes by the inter-annual 3 year processes coherence with Teleconnection Indexes [15].

In the Morlet Wavelet power spectrum (Figure 3(a)) it was observed a high variability band between 2-4 month (64-128 days) scale-period. On this band the WT was oscillating between time-periods with high and low synergism emphasizing a high frequency flood pulse. Even removing the annual variability, there was a remaining peak in this period (Figure 3(f)). Also it was possible to observe the 3-year processes behaviour into the global wavelet spectrum and another peak on about 6 years for the all series plotted. These 3 year processes, for example, have been related to the South Oscillation Index, to the Sea Surface Temperature and other Teleconnection Indexes [9, 14-16].

On the other hand, from the decadal global wavelet power spectrum (Figure 3(c, d, e), it was possible to observe changes in the amplitude distributions as a function of the period-scale. In particular, the three years peak have presented 


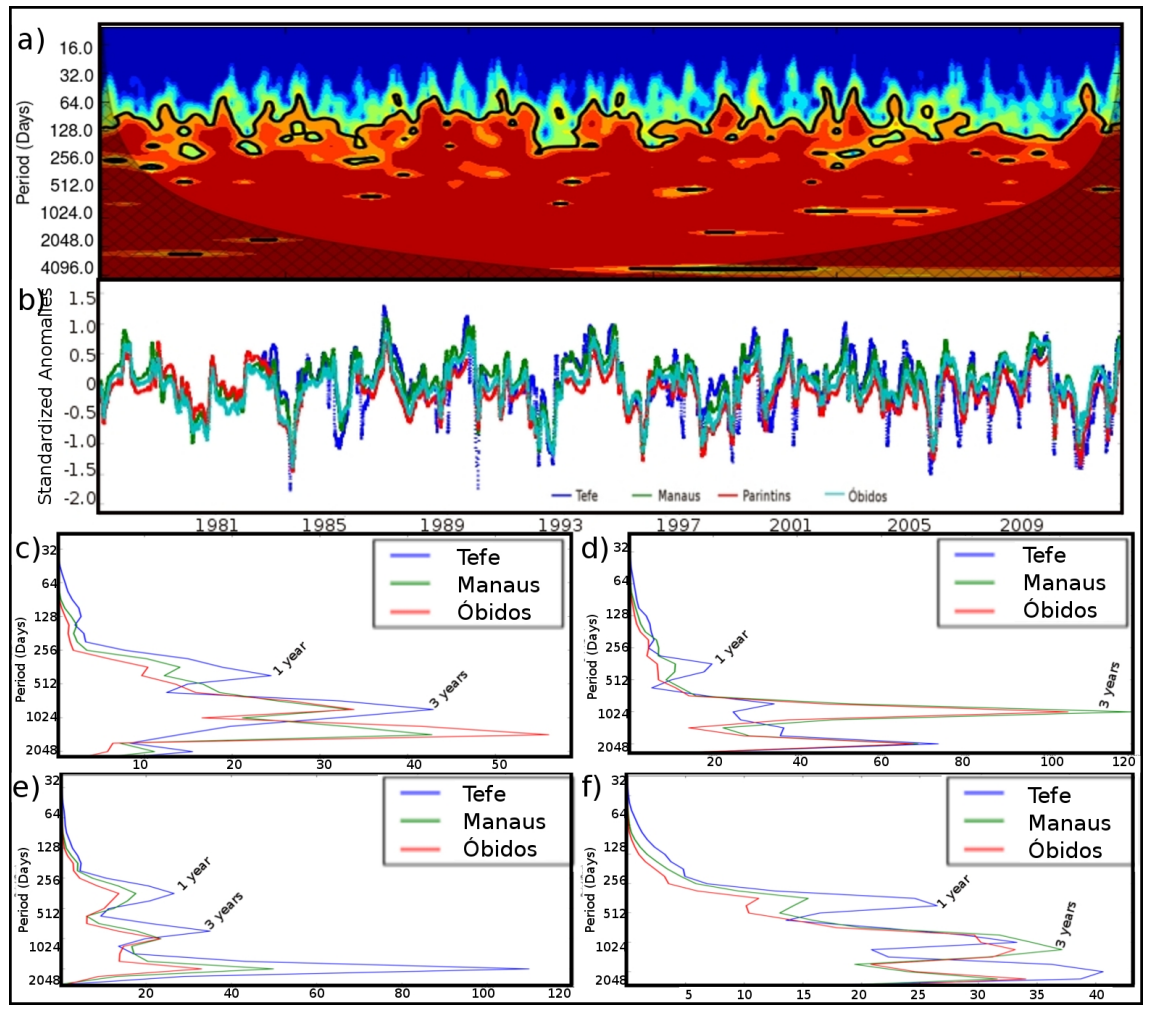

Figure 3: (a) Morlet Wavelet power spectrum for the Manaus Gauge stations. Yaxis is wavelet scale-period (days), and the $\mathrm{X}$-axis are time (years). The $\mathrm{U}$-shaped grid form shows the cone of influence. The 5\% significance level against red noise model is shown as a thick black contour. (b) Water level standardized daily anomalies $(\mathrm{cm} / \mathrm{cm})$ for Tefe, Manaus and Óbidos gauge stations. The (c), (d) and (e) boxes are the global wavelet power spectrum of these gauge stations for the three decades, 1980s, 1990s, 2000s respectively. The box (f) represents the global power spectrum for 1980-2010 time-series.

a strong amplitude variation for the last 30 years. In the infra-annual band of 32128 days minor changes were noted, suggesting that, from the 1980 s to the $2000 \mathrm{~s}$ decades the associated waves amplitude have decreased, while for the band 128256 scale-period was observed an amplitude increase. In Table 2 those changes are quantified by integrating the decadal GWPS in the 32-128 scale-period.

Even the global WT characterization were quite similar to the three gauge stations denoting that the water level variability are related to a same hydrological forcing functions, it was possible to quantify the waves amplitude for the infraannual scaled-period. The more important point in here is the possibility of 
Table 2: Integrated decadal global wavelet power spectrum in the 32-128 and 128256 scale-period.

\begin{tabular}{|c|c|c|c|}
\hline Scale-period and decade & Tefe $\left(\mathrm{cm}^{2}\right.$ day $)$ & Manaus $\left(\mathrm{cm}^{2}\right.$ day $)$ & Óbidos $\left(\mathrm{cm}^{2}\right.$ day $)$ \\
\hline $32-128,1980 \mathrm{~s}$ & 141.45 & 48.95 & 28.36 \\
\hline $32-128,2000 \mathrm{~s}$ & 114.50 & 39.35 & 23.85 \\
\hline $128-256,1980 \mathrm{~s}$ & 469.24 & 299.78 & 185.81 \\
\hline $128-256,2000 \mathrm{~s}$ & 661.66 & 490.78 & 331.53 \\
\hline
\end{tabular}

observing changes for the water level variability along the Solimões/Amazonas main channel, in particular for infra-annual scale, in the last three decades by applying the WT. A wavelet cross coherence spectrum will allow to measure the degree of wavelets coherence relation in two consecutive gauge stations as it is going to be presented in the next section.

\section{Time-scale relationship between two signals}

Dealing with non-stationary processes, as in hydrology, the use of a timefrequency representation of the signals is suggested. Such coherence highlights the temporal variations of the correlation between two signals and allows the detection of transient of high covariance [15]. To overcome the problem inherent to nonstationary signals, it has been proposed to introduce the wavelet coherence [10]. The wavelet coherence is a cross wavelet power and reveals areas with high common power [11]. This means how coherent the cross wavelet transform of two time series are in the time-frequency space. Regardless of the scale, wavelet coherence of water level between consecutive gauge stations first reflects a global coherence within the $95 \%$ of confidence interval, especially for the ManausÓbidos pairwise standardized anomalies (Figure 4(a,b)).

The wavelet coherence between consecutive gauge stations highlights a near permanent coherence for annual processes as expected, this means that hydroclimatological cycle are invariable throughout the time. In the Figure 4(a,b) it can be observed that the $5 \%$ significant coherence starts next to a month period, denoting that high frequency processes on each gauge station are independent and stochastic. When examining a scale-period 28-128-days processes, ManausÓbidos wavelet coherence values are higher than 0.9 , whereas the wavelet coherence of Tefe-Manaus water level is lower, more intermittent and higher values lies between 0.80 and 0.90 . The WT variability related to this scale-period is presented in the Figure 4(c,d) for providing a better understanding of how the WT amplitude influences in the WCC throughout the time-series.

In the Tefe-Manaus river stretch the low coherence is associated to the gauges localization (Figure 1), Tefe is placed near the Solimões/Amazon river source and it is influenced by different rainfall regimes. On the other hand, the Manaus gauge 


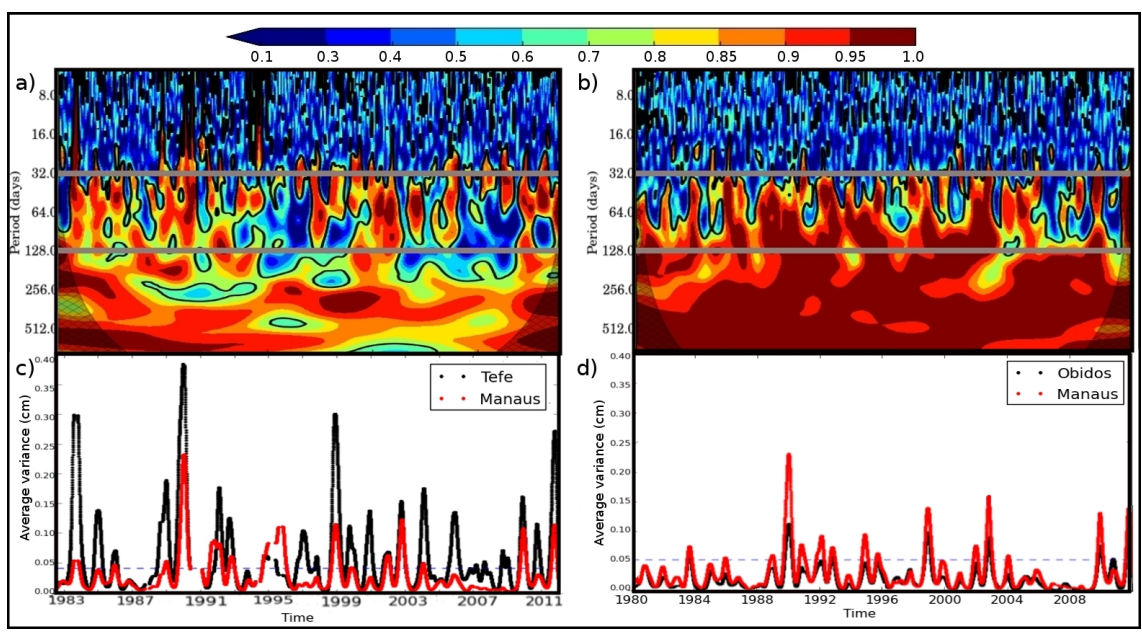

Figure 4: Wavelet Coherence power spectrum (WCPS) of the water level standardized daily anomalies relations between consecutive Gauge stations: (a) Tefe-Manaus, (b) Manaus-Óbidos. The U-shaped grid form shows the cone of influence. The 5\% significance level against red noise model is shown as a thick black contour. The grey line into the WCPS denotes the 32-128-days scale-average power zoom from the Morlet wavelet transform variance: (c) Tefe and Manaus, (d) Manaus and Óbidos.

station is influenced by two large rivers Negro and Solimões. In the ManausÓbidos river stretch both gauges are influenced by the same rivers and this feature is captured by the WT of the series and denotes a hight coherence in the WCC between these gauges.

For decadal analysis in the 28-128-days scale-period, for the Tefe-Manaus pairs was observed the strongest WCC during the 1980s decade. This might be related to the gaps into the data series and the pairwise selection of the available data. From 1990s to 2000s decades this coherence is lower in average throughout the time-series, but punctually when the WT amplitude signal were in face the coherence values become higher (Figure $4(\mathrm{a}, \mathrm{c})$ ). This characteristic suggest that since 1990 the environmental factors affecting the relationship between TefeManaus consecutive gauge stations remain constant too.

In the Manaus-Óbidos pair was observed that even with low amplitude the WT variability 32-128-days scale-period were in face almost all the 1980s and 1990s decades, so the WCC average values were high and almost permanent throughout the time-series (Figure 4(b,d)) and for the 2000s decade was observed a WCC average value diminution. This feature could be explained by the waves flattened because of the relative 32-128-days reduction and 64-256-days increase in the waves amplitude for the last three decades (Table 2). This characteristic might 
be associated with land cover changes in the floodplains area, for example, with the forest removal the system responds more quickly to water ingress, by diffuse or concentrated input, but the water remain in the system more time because of environmental changes that influence into the natural water flow, for example: sediment transport and deposition, erosion and others.

\section{Final considerations}

In particular for infra-annual periods was possible to detect changes for the water level variability along the Solimões/Amazonas main channel, by applying the Morlet Wavelet Transformation (WT) and Wavelet Cross Coherence (WCC) methods. This methodology is a recent tool for hydrological analyses, in particular for the water level historical series signals have not been used before.

It was possible to quantify the waves amplitude for the WT infra-annual scaledperiod and were quite similar to the three gauge stations denoting that the water level variability are related to a same hydrological forcing functions. Changes in the WCC was detected for the Manaus-Óbidos river stretch and this characteristic might be associated with land cover changes in the floodplains.

This study hypothesizes that the progressive forest removal in the Solimões/Amazonas floodplain in the last 30 years might be the main environmental factor affecting time variability in the correlation coefficient. The next step is to test this hypotheses by integrating land cover changes into the floodplain along the time with hydrological modelling simulations.

\section{Acknowledgements}

The authors are grateful for the financial and operational support from the Brazilian agencies FAPESP (São Paulo Research Foundation, grants 2011/00250-1 and 2012/21877-5) and INPE (National Institute for Space Research). Also we would like to thank the anonymous reviewers for their constructive comments.

\section{References}

[1] Junk, W.J., The central Amazon floodplain: Ecology of a pulsing system. Springer: Berlin, 1997.

[2] Alcântara, H., Novo, E., Stech, J., Lorenzzetti, J., Barbosa, C., Assireu, A., \& Souza, A., A contribution to understanding the turbidity behaviour in an Amazon floodplain. Hydrology and Earth System Sciences, 14(2), pp. 351364, 2010.

[3] Papa, F., Güntner, A., Frappart, F., Prigent, C. \& Rossow, W.B., Variations of surface water extent and water storage in large river basins: A comparison of different global data sources. Geophysical Research Letters, 35(11), p. L11401, 2008. 
[4] Hess, L., Melack, J., Novo, E.M.L.M., Barbosa, C. \& Gastil, M., Dual-season mapping of wetland inundation and vegetation for the central Amazon basin. Remote Sensing of Environment, 87, pp. 404 - 428, 2003.

[5] Renó, V.F., Novo, E.M., Suemitsu, C., Renno, C.D. \& Silva, T., Assessment of deforestation in the lower Amazon floodplain using historical landsat MSS/TM imagery. Remote Sensing of Environment, 115(12), pp. 3446 3456, 2011.

[6] Birkett, C.M., Contribution of the TOPEX NASA radar altimeter to the global monitoring of large rivers and wetlands. Water Resources Research, 34(5), pp. 1223-1239, 1998.

[7] Almeida, F.G., Calmant, S., Seyler, F., Ramillien, G., Blitzkow, D., Matos, A. \& Silva, J.S., Time-variations of equivalent water heights from Grace Mission and in-situ river stages in the Amazon basin. Acta Amazonica, 42, pp. 125 - 134, 2012.

[8] Kazezyilmaz-Alhan, C.M. \& Medina, M.A., Kinematic and diffusion waves: analytical and numerical solutions to overland and channel flow. Journal of Hydraulic Engineering, 133(2), pp. 217-228, 2007.

[9] Nobre, P., Marengo, A., Cavalcanti, I.F.A., Obregon, G., Barros, V., Camilloni, I., Campos, N. \& Ferreira, G., Seasonal to decadal predictability and prediction of South American climate. J Climate (Special Section), 19(23), pp. 5988-6004, 2006.

[10] Torrence, C. \& Compo, G., A practical guide to wavelet analysis. Bulletin of the American Meteorological Society, 79, pp. 61-78, 1998.

[11] Grinsted, A., Moore, J.C. \& Jevrejeva, S., Crosswavelet and wavelet coherence. Nonlinear Processes in Geophysics, 11, pp. 561-566.

[12] Pierro, D.M., Web2py. 1st edition, p. 246.

[13] Zhang, Q., Chong-Yu, X. \& Chen, D., Wavelet-based characterization of water level behaviors in the Pearl river estuary, China. Stoch Environ Res Risk Assess, 24, pp. 81-92, 2010.

[14] Marengo, J., Tomasella, J. \& Uvo, C., Long-term streamflow and rainfall fluctuations in tropical South America: Amazonia, eastern Brazil and northwest Peru. Journal of Geophysical Research, 103, pp. 1775-1783, 1998.

[15] Labat, D., Ronchail, J. \& Guyot, J., Recent advances in wavelet analyses: Part 2. Amazon, Parana, Orinoco and Congo discharges time scale variability. Journal of Hydrology, 314, pp. 289-311, 2005.

[16] Uvo, C.R.B., Repelli, C.A., Zebiak, S. \& Kushnir, Y., The relationship between tropical Pacific and Atlantic SST and northeast Brazil monthly precipitation. J Climate, 11, pp. 551-562, 1998. 